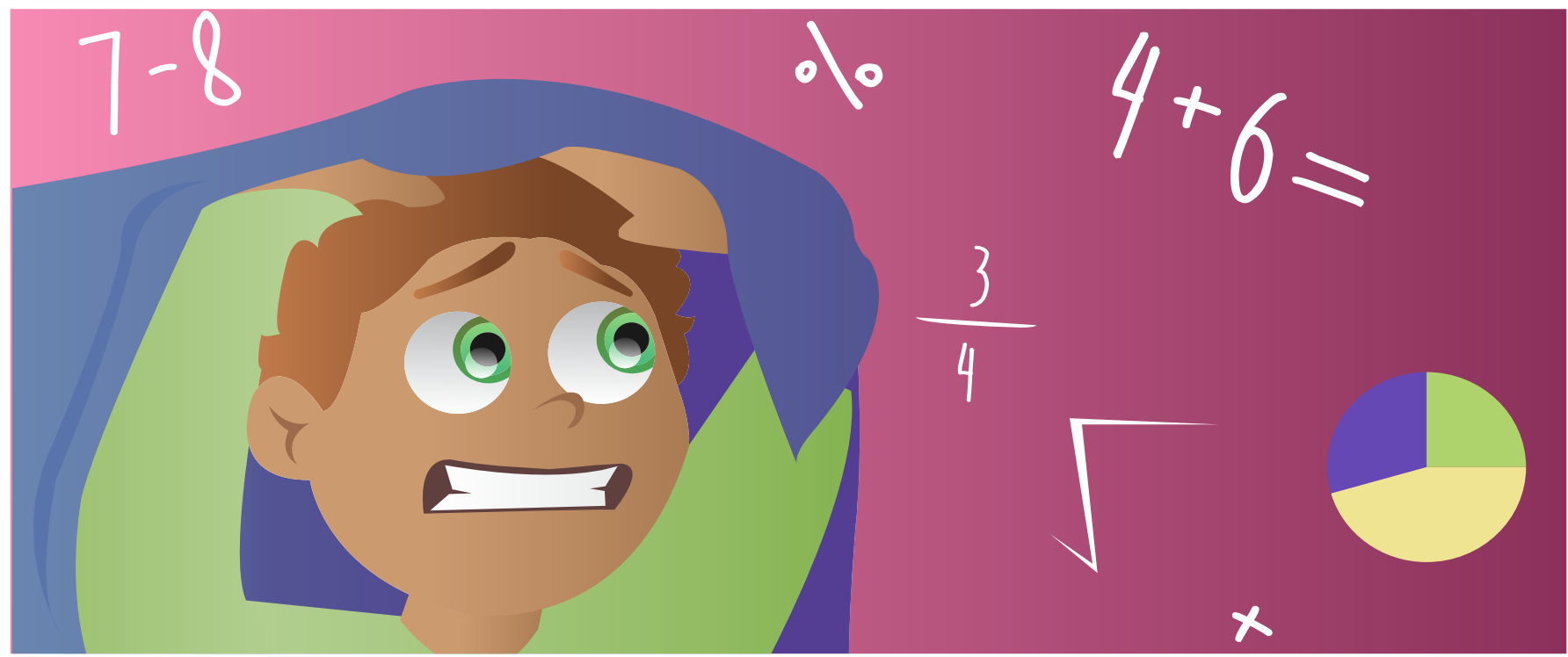

\title{
WHO IS AFRAID OF MATH? WHAT IS MATH ANXIETY? AND WHAT CAN YOU DO ABOUT IT?
}

\section{H. Moriah Sokolowski and Daniel Ansari*}

University of Western Ontario, London, ON, Canada

REVIEWED BY:

CHRISTINA

SEIX

ACADEMY

O9-10 YEARS OLD

MATH ANXIETY

The feeling of being extremely nervous when faced with doing basic mathematics.
Mathematics is a necessary skill that people use throughout their lives, such as when they travel, use money, or keep track of time. Therefore, mathematics is an important skill to learn at school. Unfortunately, many children and adults feel stressed and anxious when they have to do math. People who experience feelings of stress when faced with math-related situations may be experiencing what is called "math anxiety." Math anxiety affects many people and is related to poor math ability in school and later during adulthood. Researchers have studied how math anxiety first appears, what is happening in the brain when people experience math anxiety, and how to best help people who are suffering with math anxiety.

Have you ever felt stressed and anxious when your math teacher asks you a question? Or when you are doing your math homework? If so, you might have experienced what is called math anxiety. If you have experienced math anxiety, you are not alone. Many people feel extremely nervous when faced with a situation that requires them to do basic mathematics. Math anxiety is more than just feeling nervous about doing math. Nervousness is a sensible reaction to a situation that is actually scary. In contrast, anxiety might not make sense. This means that a person may feel anxious even though he or she knows 
that there is really no reason to feel anxious. Also, anxiety can cause physical symptoms, such as a racing heart or sweating. Usually, people who have math anxiety believe that they are bad at math and because of this, they do not like math. These feelings lead them to avoid situations in which they have to do math. Children with math anxiety often have poor math skills [1]. Adults with math anxiety often have trouble with math in their careers and everyday life [2]. Adults with math anxiety are less likely to show interest, enter, and succeed in careers relating to science, technology, engineering, and mathematics.

Because math anxiety affects many people and is related to poor math skills, it is important to understand when and how math anxiety first appears, what is happening in the brain when people are feeling anxious about math, and how to best help people with math anxiety.

\section{WHEN AND HOW DOES MATH ANXIETY FIRST APPEAR?}

Until recently, scientists and educators thought that math anxiety first appears when children begin to learn complicated mathematics (such as algebra). This would mean that young children (who do not yet do complicated math) do not experience math anxiety. However, recent research has shown that some children as young as 6 years old say that they feel anxious about math. A team of researchers asked 154 children in grades 1 and 2 questions like, "how do you feel when taking a big test in your math class?" [3] The children had to indicate how nervous they felt by pointing to a position on a scale, ranging from a very nervous face on the left to a calm face on the right. (See Figure 1 for a picture of the scale.) After answering these questions, the children took a math test that measured their math abilities. These researchers found that almost half of the children who participated in the study said that they were at least somewhat nervous about

\section{FIGURE 1}

Children used a scale that looks like this to show how nervous they would feel about math-related situations (for example, if they were asked "how do you feel when taking a big test in your math class?") by pointing to a position on the scale.

(This image is based on the Children's Math Anxiety Questionnaire found at http:// spatiallearning.org/media/ silc_pdfs/resources/ testsandinstruments/ tandi-new/Childrens Math_Anxiety_ Questionnaire.pdf.) doing math [3]. Also, children with higher math anxiety got worse scores on the math test. This research tells us that math anxiety and the relationship between math anxiety and math ability develops when children are very young.

Researchers are also interested in how math anxiety develops. Although research has shown that math anxiety and math abilities are related [1], no study so far has been able to tell us which comes first. In other words, we do not know if being bad at math causes math anxiety, or if having math anxiety makes people bad at math.

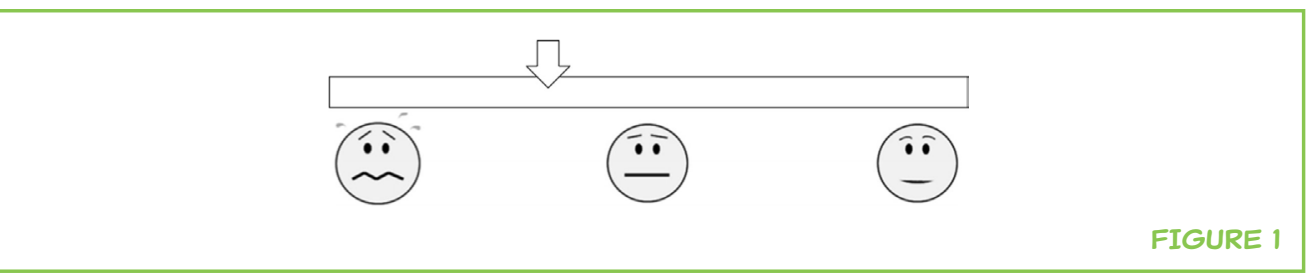


Researchers have two ideas about how math anxiety might develop. One idea is that children who struggle with learning numbers when they are very young are more likely to develop math anxiety when they start going to school. This idea has not yet been tested in children. Another idea is that math anxiety develops in children who experience certain kinds of social situations that influence the child's thoughts or feelings. This means that the child's emotions, opinions, or behaviors are affected by things that other people say or do. One study that gives an example of this showed that teachers with high math anxiety were more likely to have students with poorer math achievement at the end of the school year [4]. This study suggests that the way the teacher acted somehow affected the math ability of the students. Although researchers have not yet answered the question of what comes first, math ability or math anxiety, there have been many important discoveries that have given us hints about when and how math anxiety appears.

\section{WORKING} MEMORY

A part of the memory system that is used to remember and hold information in your mind so you can use it when doing activities.

\section{WHAT IS HAPPENING IN THE BRAIN WHEN A PERSON IS EXPERIENCING MATH ANXIETY?}

To better understand how math anxiety develops and how to help people who suffer with it, we need to understand what is happening in brain while a person with math anxiety is doing math. One idea is that the human brain can only process a certain amount of information at a time. A system in the brain that allows us to process information is called working memory. Working memory is a part of the human memory system that allows us to remember and think about several things at the same time. This skill is very important for doing math. For example, if a teacher reads out a math problem, the student must hold all numbers in his or her mind, consider the steps needed to solve the problem, and write out the answer at the same time. Researchers think that maybe, when people feel anxious, the math anxiety that they feel is using up some of their working memory, so they do not have enough working memory left to solve the math problem. Maybe the working memory that is being used for the anxiety would have been used for solving the math problem if those people did not feel so anxious [3]. In other words, math anxiety causes students to think and worry about how afraid they feel of math, which occupies the working memory resources that they would otherwise use to do the math problems. This idea that math anxiety uses working memory has been supported by research studies. Importantly, researchers have reported that children who have a high level of working memory do better on math tests than children with a low level of working memory.

Researchers have also examined how hard different parts of the brain are working while children with either high or low math anxiety solve challenging math problems [5]. These researchers asked a group of 7- to 9-year-old children 
MAGNETIC RESONANCE IMAGING (MRI)

An MRI is a machine that uses a strong magnet to create pictures of your brain.

\section{FUNCTIONAL}

MAGNETIC

RESONANCE

IMAGING (FMRI)

A tool that measures which brain regions are activated while you complete different activities in an MR scanner, such as adding and subtracting.

\section{BRAIN}

\section{ACTIVATION}

A measure of how hard a region of the brain is working during a specific task. If a brain region is working hard, there will be more brain activation.

\section{FIGURE 2}

This is a picture of an MRI scanner.

An MRI scanner is a large donut-shaped magnet that often has a tunnel in the center. The person being studied is placed on a comfortable table that slides into the tunnel. The person then stays very still while the MRI scanner works with a computer to produce clear black-andwhite images of the brain. These images can be taken while people do activities to show which areas of the brain are activated. with and without math anxiety to do some math problems while they were in a device called a magnetic resonance imaging (MRI) scanner [5]. An MRI scanner is a machine that can be used to measure how hard each region of the brain is working during a specific task using a tool called functional magnetic resonance imaging (fMRI). (See Figure 2 for a picture of an MRI scanner.) This measurement is called "brain activation." If a brain region is working hard, there will be more brain activation. These researchers found that a part of the brain called the amygdala is more activated (working harder) in children with high math anxiety than in children with low math anxiety. Also, in children with high math anxiety, the areas of the brain that deal with working memory and mathematical processing (called the dorsolateral prefrontal cortex and the intraparietal sulcus) are less activated (working less hard) compared with those brain areas in children who have low math anxiety [5]. The amygdala is a small almond-shaped structure in the lower middle part of the brain and it is important for experiencing and processing emotions, including fear and anxiety. The dorsolateral prefrontal cortex is a larger part of the brain located at the very front of the brain, and it is involved in many complicated behaviors, such as planning and decision making. The intraparietal sulcus is a brain region near the top of the brain that is important for mathematics and paying attention. (See Figure 3 for a picture of where these brain regions are located.) So, overall, this study suggests that when children solve math problems, those children with high math anxiety activate brain regions involved in anxiety, while those children with low math anxiety activate brain regions that are involved with solving math problems.

\section{HOW CAN WE HELP PEOPLE WITH MATH ANXIETY?}

One of the main goals of understanding what causes math anxiety and how math anxiety affects the brain is to find ways to help people with math anxiety and ultimately to prevent it from happening. Some researchers have created

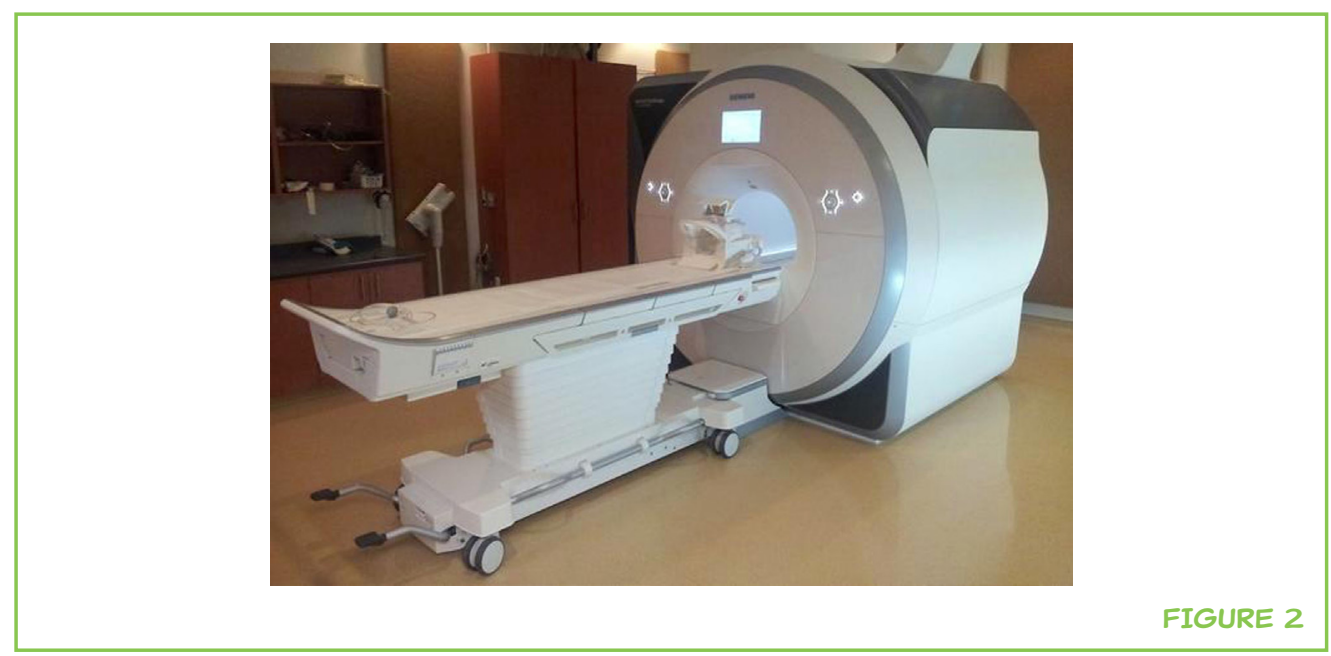




\section{FIGURE 3}

This picture shows the brain regions that are more activated (working harder) and the brain regions that are less activated (working less hard) in individuals with high math anxiety when they do math problems.

\section{INTERVENTION}

A tool or program that is given to people with the goal of helping them improve or get better at a skill.

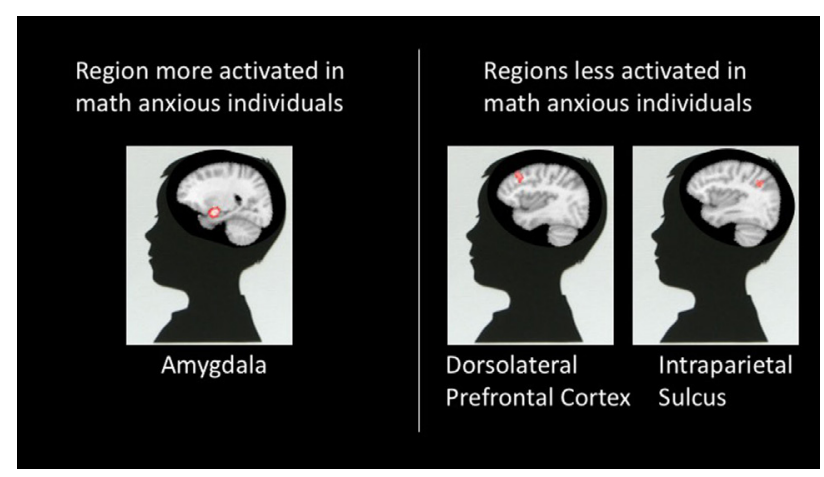

FIGURE 3

tools to help people with math anxiety. These tools are called interventions. For example, researchers have made interventions based on research showing that writing down thoughts and feelings beforehand can make people feel less nervous when taking tests. Researchers thought that if children wrote down their thoughts and feelings, those feelings would not occupy working memory while the children were completing a math test. So, the researchers did an intervention where they asked children with math anxiety to write about their math-related worries. These researchers found that, when students wrote about their math-related worries, their math test scores improved [6]. A different group of researchers showed that if college students with math anxiety did some breathing exercises to calm them down before a math test, they felt more calm and their scores on the test improved [7]. Together, these intervention studies provide scientific evidence for ways that we can help people with math anxiety. This research is very promising because it tells us that people with math anxiety can be helped-they are not stuck with math anxiety for life.

\section{CONCLUSION}

Since we know that people with math anxiety face challenges in their math classes, careers, and everyday lives, many different researchers have worked to learn more about math anxiety. Researchers continue to make progress in this area. Research on math anxiety has shown that it develops early, and that it is related to both social situations and brain processes like working memory. Also, individuals with math anxiety show more brain activation in brain regions involved with negative emotions, and less brain activation in brain regions involved with mathematical thinking. Researchers have also started to test possible interventions that seem to help individuals suffering with math anxiety. However, there is still a lot of work to be done to discover how math anxiety first appears, what causes only some people to have it, and how we can help people who have math anxiety. For now, whether you are experiencing math anxiety or not, talk to your fellow students and your teachers about math 
anxiety. It is important to have conversations about your emotional reactions to math because this is the first step toward helping to reduce the potentially harmful effects of math anxiety.

\section{REFERENCES}

1. Wu, S. S., Barth, M., Amin, H., Malcarne, V., and Menon, V. 2012. Math anxiety in second and third graders and its relation to mathematics achievement. Front. Psychol. 3:1-11. doi:10.3389/fpsyg.2012.00162

2. Ma, X. 1999. A meta-analysis of the relationship between anxiety toward mathematics and achievement in mathematics. J. Res. Math. Educ. 30:520-40. doi:10.2307/749772

3. Ramirez, G., Gunderson, E. A., Levine, S. C., and Beilock, S. L. 2013. Math anxiety, working memory, and math achievement in early elementary school. J. Cogn. Dev. 14:187-202. doi:10.1080/15248372.2012.664593

4. Beilock, S. L., Gunderson, E. A., Ramirez, G., and Levine, S. C. 2010. Female teachers' math anxiety affects girls' math achievement. Proc. Natl. Acad. Sci. U.S.A. 107:1860-3. doi:10.1073/pnas.0910967107

5. Young, C. B, Wu, S. S., and Menon, V. 2012. The neurodevelopmental basis of math anxiety. Psychol. Sci. 23:492-501. doi:10.1177/0956797611429134

6. Park, D., Ramirez, G., and Beilock, S. L. 2014. The role of expressive writing in math anxiety. J. Exp. Psychol. Appl. 20:103-11. doi:10.1037/xap0000013

7. Brunyé, T. T., Mahoney, C. R., Giles, G. E., Rapp, D. N., Taylor, H. A., and Kanarek, R. B. 2013. Learning to relax: evaluating four brief interventions for overcoming the negative emotions accompanying math anxiety. Learn. Individ. Differ. 27:1-7. doi:10.1016/j.lindif.2013.06.008

SUBMITTED: 29 March 2017; ACCEPTED: 25 September 2017; PUBLISHED ONLINE: 17 October 2017.

EDITED BY: Robert T. Knight, University of California, Berkeley, United States

CITATION: Sokolowski H.M and Ansari D (2017) Who Is Afraid of Math? What Is Math Anxiety? And What Can You Do about It? Front. Young Minds 5:57. doi:10.3389/ frym.2017.00057

CONFLICT OF INTEREST STATEMENT: The authors declare that the research was conducted in the absence of any commercial or financial relationships that could be construed as a potential conflict of interest.

COPYRIGHT @ 2017 Sokolowski and Ansari. This is an open-access article distributed under the terms of the Creative Commons Attribution License (CC BY). The use, distribution or reproduction in other forums is permitted, provided the original author(s) or licensor are credited and that the original publication in this journal is cited, in accordance with accepted academic practice. No use, distribution or reproduction is permitted which does not comply with these terms. 


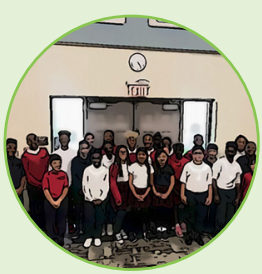

\section{REVIEWED BY}

\section{CHRISTINA SEIX ACADEMY, 09-10 YEARS OLD}

CSA is an innovative urban Pre-K-8 independent school focused on providing students from underserved communities with a holistic education, critical habits of mind, and an engaging learning environment. A scholarship is awarded to every child entering the academy to cover tuition, books, school uniforms, meals, door to door transportation, as well as room and board for students that choose to board in 4th to 8th grade. Our goal is to ensure that all students move from "Potential to Achievement" and graduate inspired to "Pay it Forward" like our Founder, Christina Seix.

\section{AUTHORS}

\section{H. MORIAH SOKOLOWSKI}

I am a Ph.D. student at the University of Western Ontario. I am interested in how young children learn basic number skills such as how to count, or what " 3 " means. I want to understand what happens in the brain while children develop and learn math. I also want to learn about why some children like math and do well in math, while others feel nervous about math and find it hard. When I am not doing research, I like to sing in a choir, do yoga, and hang out with my cat.

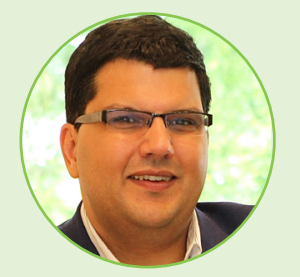

\section{DANIEL ANSARI}

I am interested in how our brains process numbers and how we use them. We use numbers all the time. I want to know how the human brain is able to know about numbers and why some children find numbers so hard to understand. What is different about their brains and why do some people find numbers really scary while others love to use them?

*daniel.ansari@uwo.ca 